Print ISSN: 2234-3040 / Online ISSN 2234-3059

doi:10.13106/eajbm.2017.vol7.no4.35

\title{
Prediction of Sales on Some Large-Scale Retailing Types in South Korea*
}

\author{
Dong-Bin Jeong** \\ Received: July 18, 2017. Revised: August 4, 2017. Accepted: October 15, 2017.
}

\section{Abstract}

Purpose - This paper aims to examine several time series models to predict sales of department stores and discount store markets in South Korea, while other previous trial has performed sales of convenience stores and supermarkets. In addition, optimal predicted values on the underlying model can be got and be applied to distribution industry.

Research design, data, and methodology - Two retailing types, under investigation, are homogeneous and comparable in size based on 86 realizations sampled from January 2010 to February in 2017. To accomplish the purpose of this research, both ARIMA model and exponential smoothing methods are, simultaneously, utilized. Furthermore, model-fit measures may be exploited as important tools of the optimal model-building.

Results - By applying Holt-Winters' additive seasonality method to sales of two large-scale retailing types, persisting increasing trend and fluctuation around the constant level with seasonal pattern, respectively, will be predicted from May in 2017 to February in 2018.

Conclusions - Considering 2017-2018 forecasts for sales of two large-scale retailing types, it is important to predict future sales magnitude and to produce the useful information for reforming financial conditions and related policies, so that the impacts of any marketing or management scheme can be compared against the do-nothing scenario.

Keywords: Large-Scale Retailing Type, ARIMA Model, Exponential Smoothing Method, Optimal Forecasts.

JEL Classifications: C22, C53, D39, M21.

\section{Introduction}

In general, we often define large retail trade as "a type in which either single type of goods or various goods is made available to a large number of customers in a big shop under a single roof or may be made available at the convenience of customers". Industry data reported that major South Korean discount retailers found their sales come close 1.8 percent in 2016 to exceed 40 trillion won, by virtue of an increase in new outlet. In recent time, large retailing industry in Korea has suffered slowly-moving sales growth because of slower-run discount store markets from operating. Jeong (2016) investigated the optimal forecasting for sales of small-scale retailing types such as convenience stores and supermarkets in South Korea. He found that the predicted values of sales at convenience stores can have

* This work was supported by the Research Institute of Natural Science of Gangneung-Wonju National University.

** Professor, Department of Information Statistics and Research Institute of Natural Science, Gangneung-Wonju National University, Korea. Tel: +82-33-640-2274, E-mail: dj@gwnu.ac.kr the pattern of the precipitous and lasting increase, although forecasts for sales at supermarkets can be expected to be lagging over 2017 by utilizing a seasonal ARIMA-Intervention model. Kim et al. (2014) tried to find which factors can affect sales on department stores in South Korea, and measured the influence both position and non-position factors. In particular, they showed that 'area of sales property', 'parking space' and 'number of luxury goods' are positively correlated with profit of department store. Youn (2004) set a clear vision on distribution markets by considering the fact that most jobs in South Korea are focused on the marketing field and analyzed the distribution industry from the internal viewpoints of distribution companies. In this research, we analyze several univariate time series models such as ARIMA model, exponential smoothing method, so that we can forecast the upcoming values of two large-scale retailing types in South Korea.

A short outline for time series models under consideration will, in section 2, be shown, together with model-fit statistics and in section 3 , the results of several time series analyses and forecasts for sales of two large-scale retailing types will be presented. Finally, summary and concluding remarks will 
be stated.

\section{Time Series Analysis}

In order to forecast the future value of sales at department stores as well as discount store markets in South Korea, the following time series models can be considered:

\subsection{ARIMA(Autoregressive Integrated Moving Average) Model}

(Anderson, 1971; Bianchi et al, 1998; Bowerman et al, 2005; Box et al, 1994; Brown, 1959; Fuller, 1976; Hamiltan, 1994; Jeong, 2010; Jeong, 2016; Pankraz, 1983)

An autoregressive integrated moving average (ARIMA) model forecasts a value(s) in a dependent time series as a linear combination of its own past values, past shocks, and past and current values of other series, and can be expressed as follows:

$$
y_{t}=\frac{\Theta_{Q}\left(B^{s}\right) \theta_{q}(B)}{\Phi_{p}\left(B^{s}\right) \Phi_{p}(B)(1-B)^{d}\left(1-B^{s}\right)^{D}} \epsilon_{t},
$$

$$
\begin{aligned}
& \text { where } \Theta_{Q}\left(B^{s}\right)=\left(1-\Theta_{s} B^{s}-\Theta_{2 s} B^{2 s}-\cdots-\Theta_{Q s} B^{Q s}\right), \\
& \Phi_{P}\left(B^{s}\right)=\left(1-\Phi_{s} B^{s}-\Phi_{2 s} B^{2 s}-\cdots-\Phi_{P_{s}} B^{P s}\right) \\
& \theta_{q}(B)=\left(1-\theta_{1} B-\theta_{2} B^{2}-\cdots-\theta_{q} B^{q}\right) \\
& \Phi_{p}(B)=\left(1-\Phi_{1} B-\Phi_{2} B^{2}-\cdots-\Phi_{p} B^{p}\right)
\end{aligned}
$$

and $\epsilon^{\prime} s$ are white noises.

Here, $(p, d, q)$ and $(P, D, Q)_{s}$ are non-seasonal order and seasonal order, respectively (Anderson, 1971; Choi, 1992; Fuller, 1976; Hamilton, 1994; Pankratz, 1983; Pankratz, 1991; Tsay \& Tiao, 1984).

\subsection{Exponential smoothing method}

(Anderson, 1994; Archibald, 1990; Archibald \& Koehler 2003; Bartolomei \& Sweet, 1989; Brown, 1963; Broze \& Mélard, 1990; Gardner, 1985; Gardner, 2006; Jeong, 2009; Roberts, 1982; Rosas \& Guerrero, 1994; Trigg \& Leach, 1967; Winters, 1960).

This method is one of most widely used models to make a smoothed time series. While in single moving averages the past realizations are weighted equally, exponential smoothing allots exponentially decreasing weights as the realizations is older. That is to say, recent realizations are assigned relatively more weight in predicting than more remote realizations.

\subsubsection{Simple exponential smoothing method}

This method is used for forecasting a time series when there is no trend or seasonal pattern, but the mean (or level) of the time series is slowly changing over time. This is utilized for short-range prediction, usually just one-time period into the future. The forecast for the next period is

$$
\hat{\mathrm{y}}_{t+1}=\hat{\mathrm{y}}_{t}+\alpha\left(\hat{\mathrm{y}}_{t}-\hat{\mathrm{y}}_{t}\right)
$$

where ais a smoothing constant between 0 and 1 .

\subsubsection{Holt's linear method}

Holt (1957) extended the previous exponential smoothing to linear trends exponential smoothing, for the purpose of predicting realizations with trends. The forecast for this method is found that using two smoothing constants, $\alpha, \beta$ (with constants between 0 and 1), and the following equations:

Level: $L_{t}=\alpha y_{t}+(1-\alpha)\left(L_{t-1}+Q_{t-1}\right)$,

Slope: $Q_{t}=\beta\left(L_{t}-L_{t-1}\right)+(1-\beta) Q_{t-1}$,

Forecasts: $\hat{\mathrm{y}}_{t+j, t}=L_{t}+j Q_{t}$,

where $L_{t}$ and $Q_{t}$ are estimates of the level and the slope of the series at time $t$, respectively.

\subsubsection{Damped linear trend method}

This method is a modification of Holt's linear method to allow the "damping" of trends. The equations for this method are

$$
\begin{aligned}
& \text { Level : } L_{t}=\alpha\left(\frac{y_{t}}{s_{t-m}}\right)+(1-\alpha)\left(L_{t-1}+Q_{t-1}\right), \\
& \text { Slope: } Q_{t}=\beta\left(L_{t}-L_{t-1}\right)+(1-\beta) \phi Q_{t-1}, \\
& \text { Forecasts : } \hat{\mathrm{y}}_{t+j, t}=L_{t}+\sum_{i=1}^{j} \phi_{i} j Q_{t}
\end{aligned}
$$

The next two Holt-Winters methods are based on three smoothing equation - level, slope and seasonality, depending on whether seasonality is modeled in a multiplicative or an additive way.

\subsubsection{Multiplicative seasonality method}

We can use this model in case that realizations increase, so does the seasonal pattern. 
Level: $L_{t}=\alpha y_{t}+(1-\alpha)\left(L_{t-1}+\phi Q_{t-1}\right)$,

Slope: $Q_{t}=\beta\left(L_{t}-L_{t-1}\right)+(1-\beta) Q_{t-1}$,

Seasonality: $S_{t}=\delta\left(\frac{y_{t}}{L_{t-1}+b_{t-1}}\right)+(1-\delta) S_{t-j}$,

Forecasts: $\hat{\mathrm{y}}_{t+j, t}=\left(L_{t}+j Q_{t}\right) S_{t-j+|(j-1) \bmod j|+1}$.

\subsubsection{Additive seasonality method}

We can use this model in case that the magnitude of the type of seasonality is fixed as the series fluctuates.

Level: $L_{t}=\alpha\left(y_{t}-S_{t-m}\right)+(1-\alpha)\left(L_{t-1}+Q_{t-1}\right)$,

Slope: $Q_{t}=\beta\left(L_{t}-L_{t-1}\right)+(1-\beta) Q_{t-1}$,

Seasonality: $S_{t}=\delta\left(y_{t}-L_{t-1}+b_{t-1}\right)+(1-\delta) S_{t-j}$

Forecasts: $\hat{y}_{t+j, t}=\left(L_{t}+j Q_{t}\right) S_{t-j+|(j-1) \bmod j|+1}$

For the purpose of satisfying optimal properties of the underlying model, the following statistics can be exploited:

\subsection{Model-fit measures to select the optimal model}

(Chatfield, 1988; Chatfield, 1993; Chatfield, 1995; Chatfield, 1996; Chatfield, 1997; Chatfield, 2002; Hurcich \& Tsai, 1990).

- Stationary R-squared. This measure is better than ordinary R-squared when a trend or seasonality in time series can be detected. If it is a negative value, then we can conclude that the baseline model is dominant to the model under consideration.

- R-squared. A statistic of the proportion of the whole variation in the time series accounted for by the model. This measure can be valid when the time series satisfy stationarity. A negative value of this measure means that the baseline model is dominant to the model under consideration, while a positive value does that the underlying model is more appropriate than the baseline one.

- Root Mean Square Error (RMSE). A measure of how much a response variable shifts from its model-forecasted level.

- Mean Absolute Percentage Error (MAPE). This measure is not dependent on the units detected and be taken advantage of comparing the time series with different ones.

- Mean absolute error (MAE). A measure how much the time series fluctuate its model-predicted level.

- Maximum Absolute Percentage Error MaxAPE). The biggest predicted error, depicted as a percentage. This measure is useful to estimate a worst situation for predicted values.
- Maximum Absolute Error (MaxAE). This measure is useful to estimate the worst-case scenario for predicted values.

- Normalized Bayesian Information Criterion (BIC). This statistic is a score focused on the MSE and covers a disadvantage for the number of coefficients in the model under consideration and the length of the time series.

\section{Summary and Research Results}

\subsection{Summary}

First, several time series models, in this work, are applied to obtain optimal forecasts by using TSAPPLY and MODELFIT procedures in IBM SPSS 23.0.

$<$ Table $1>$ shows that the main descriptive statistics of sales at both discount store markets and department stores in South Korea for 86 realizations from January in 2010 to February in 2017, including mean, standard deviation, minimum and maximum.

$<$ Table $1>$ Summary statistics

\begin{tabular}{|c|c|c|c|c|c|}
\hline $\begin{array}{c}\text { Statistic } \\
\text { Variable(Sales) }\end{array}$ & $\mathbf{N}$ & Minimum & Maximum & Mean & $\begin{array}{c}\text { Std. } \\
\text { Deviation }\end{array}$ \\
\hline $\begin{array}{c}\text { Discount Stores } \\
\text { Markets }\end{array}$ & 86 & $2,847,287$ & $4,982,538$ & $3,827,226.4$ & $455,347.7$ \\
\hline $\begin{array}{c}\text { Department } \\
\text { Stores }\end{array}$ & 86 & $1,653,658$ & $3,040,996$ & $2,369,966.5$ & $312,886.9$ \\
\hline
\end{tabular}

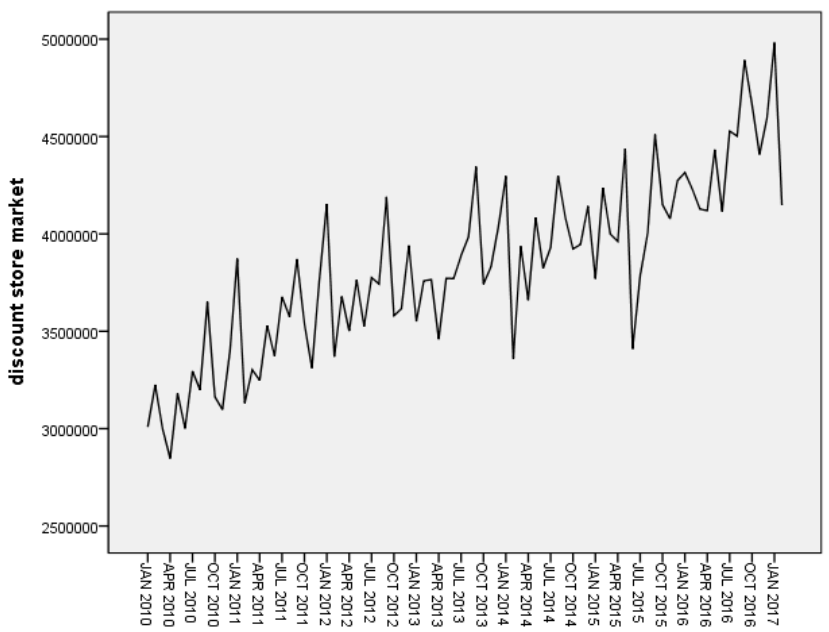

$<$ Figure 1> Time-plot of sales at discount store markets 


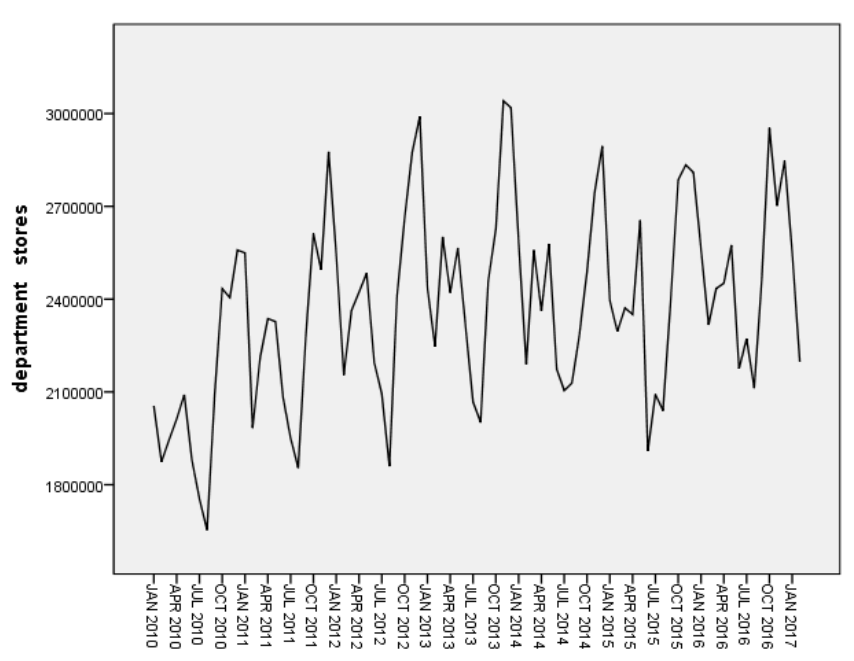

<Figure 2> Time-plot of salesat department stores

From both <Figure $1>$ and <Figure 2>, we may find out that there exists seasonal variation with displaying periodic behavior within the underlying series. While the level seems to fluctuate around the sample mean in <Figure 2>, the slope in <Figure $1>$ increases steady and persistently. That is, the series of <Figure 1>appears to need to be differencing to accomplish stationarity in building ARIMA models.

\subsection{Findings of Sales at Discount Store Markets}

Considering the pattern of the trend and the type of seasonality from <Figure 1>, Holt's linear, damped linear and Holt-Winters' additive seasonality method can be considered, we can compare optimal dominance among them in terms of model-fit measures in <Table 2>. Similarly, we may take into account ARIMA models, $\operatorname{ARIMA}(0,0,1)$ $(0,0,1)_{12}$ and $\operatorname{ARIMA}(3,1,0)(0,0,1)_{12}$, by applying an iterative procedure based on three stages - identification, estimation, and diagnostic checking, so that we can find the optimal ARIMA model.

<Table 2> Optimality selection for sales at discount store markets in terms of exponential smoothing methods

\begin{tabular}{|c|c|c|c|}
\hline $\begin{array}{c}\text { Model } \\
\text { Goodness-of fit } \\
\text { measures }\end{array}$ & $\begin{array}{c}\text { Winter's additive } \\
\text { seasonality }\end{array}$ & Holt's linear & $\begin{array}{c}\text { Damped } \\
\text { linear }\end{array}$ \\
\hline Stationary R-squared & $\mathbf{. 8 0 8}$ & .830 & .508 \\
\hline R-squared & $\mathbf{. 8 4 6}$ & .692 & .697 \\
\hline RMSE & $\mathbf{1 8 0 , 9 9 6 . 8 0}$ & $254,219.21$ & $253,518.63$ \\
\hline MAPE & $\mathbf{3 . 3 7}$ & 5.09 & 5.04 \\
\hline MAE & $\mathbf{1 2 7 , 9 4 9 . 1 4}$ & $194,521.74$ & $192,808.83$ \\
\hline MAXAPE & $\mathbf{1 5 . 3 6}$ & 21.94 & 22.35 \\
\hline MAXAE & $\mathbf{5 2 3 , 6 2 5 . 9 6}$ & $748,094.16$ & $762,120.28$ \\
\hline Normalized BIC & $\mathbf{2 4 . 3 7}$ & 24.99 & 25.04 \\
\hline
\end{tabular}

$<$ Table 3> Optimality selection for sales at discount store markets in terms of ARIMA models

\begin{tabular}{|c|c|c|}
\hline $\begin{array}{c}\text { Model } \\
\text { Goodness-of fit } \\
\text { measures }\end{array}$ & ARIMA(0,1,1)(0,0,1) $)_{\mathbf{1 2}}$ & ARIMA(3,1,0)(0,0,1) $\mathbf{1 2}$ \\
\hline Stationary R-squared & $\mathbf{. 5 4 8}$ & .507 \\
\hline R-squared & $\mathbf{. 7 1 2}$ & .686 \\
\hline RMSE & $\mathbf{2 4 3 , 9 9 3 . 9 7}$ & $256,414.11$ \\
\hline MAPE & $\mathbf{4 . 8 3}$ & 5.09 \\
\hline MAE & $\mathbf{1 8 4 , 2 6 3 . 5 9}$ & $194,660.06$ \\
\hline MAXAPE & $\mathbf{2 0 . 9 2}$ & 21.95 \\
\hline MAXAE & $\mathbf{7 1 3 , 3 0 3 . 3 3}$ & $748,364.15$ \\
\hline Normalized BIC & $\mathbf{2 4 . 9 7}$ & 25.12 \\
\hline P-value of Box-Ljung & $\mathbf{6 6 0}$ & .659 \\
Statistic & & \\
\hline
\end{tabular}

As a result, Holt-Winters' additive seasonality method and $\operatorname{ARIMA}(0,0,1)(0,0,1)_{12}$ can be chosen, respectively, as seen from <Table 2> and <Table 3>. At last, Holt-Winters' additive seasonality method may be considered as the optimal model to forecast the forthcoming data in that it satisfies the properties that has the largest $R^{2}$, and the smallest RMSE, MAPE, MAE, MaxAPE and MAxAE.

<Table 4> Optimal forecasts and two $95 \%$ confidence limits of sales at discount store markets

\begin{tabular}{|c|c|c|c|}
\hline Time period & Forecasts & $\begin{array}{c}\text { 95\% Lower } \\
\text { Confidence Limit }\end{array}$ & $\begin{array}{c}\text { 95\% Upper } \\
\text { Confidence Limit }\end{array}$ \\
\hline MAR 2017 & $\mathbf{4 , 4 5 1 , 3 9 9}$ & $2,255,076$ & $2,656,388$ \\
\hline April 2017 & $\mathbf{4 , 3 0 7 , 4 5 6}$ & $2,204,712$ & $2,610,286$ \\
\hline May 2017 & $\mathbf{4 , 6 5 0 , 7 7 9}$ & $2,301,766$ & $2,716,772$ \\
\hline June 2017 & $\mathbf{4 , 3 3 8 , 7 2 8}$ & $1,900,891$ & $2,332,154$ \\
\hline July 2017 & $\mathbf{4 , 6 0 4 , 8 3 8}$ & $1,801,740$ & $2,257,244$ \\
\hline August 2017 & $\mathbf{4 , 6 6 5 , 6 2 8}$ & $1,657,716$ & $2,146,017$ \\
\hline Sept 2017 & $\mathbf{4 , 9 8 4 , 7 9 6}$ & $1,997,374$ & $2,527,062$ \\
\hline Oct 2017 & $\mathbf{4 , 5 8 7 , 5 3 6}$ & $2,254,731$ & $2,834,040$ \\
\hline Nov 2017 & $\mathbf{4 , 5 2 0 , 1 9 9}$ & $2,272,750$ & $2,909,338$ \\
\hline Dec 2017 & $\mathbf{4 , 7 8 5 , 2 5 1}$ & $2,339,478$ & $3,040,355$ \\
\hline Jan 2018 & $\mathbf{4 , 8 4 9 , 1 3 0}$ & $1,903,694$ & $2,675,229$ \\
\hline Feb 2018 & $\mathbf{4 , 5 3 7 , 4 9 6}$ & $1,532,668$ & $2,380,655$ \\
\hline
\end{tabular}

By applying Holt-Winters' additive seasonality method to sales at discount store markets, persisting increasing trend with seasonal pattern may be predicted from May in 2017 to February in 2018 from both <Table 4> and <Figure 3>. 


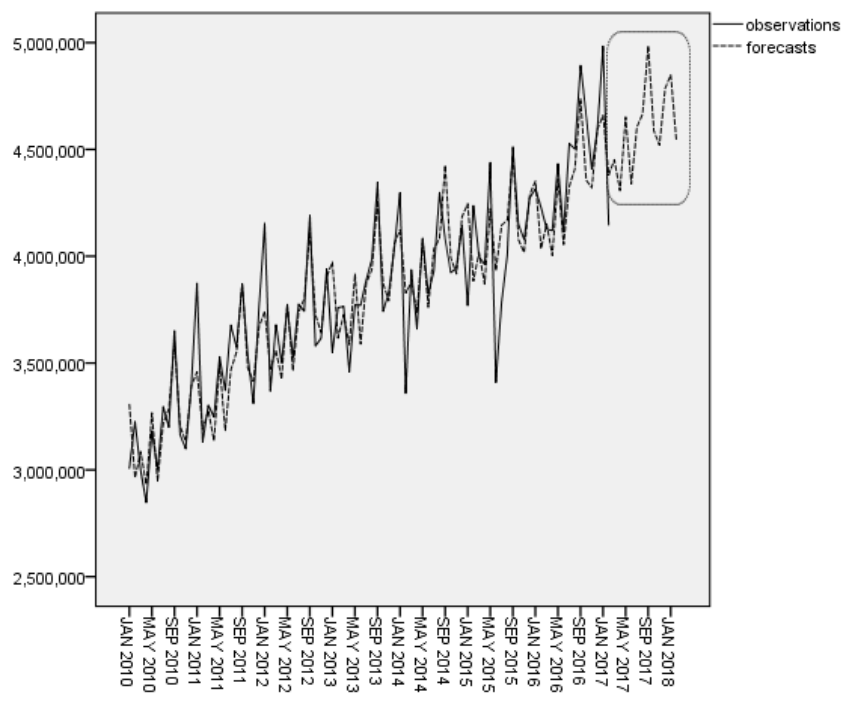

<Figure 3> Optimal forecasts of sales at discount store markets in South Korea

\subsection{Findings of Sales at Department Stores}

We can analyze and evaluate sales at department stores in South Korea, just as we do in section 3.2. Taking into account existence and pattern of seasonality from <Figure 2>, Holt-Winters' additive and Holt-Winters' multiplicative seasonality method can be allowed for. At the same time, $\operatorname{ARIMA}(1,0,0)(1,0,0)_{12}$ and $\operatorname{ARIMA}(0,0,3)(1,0,0)_{12}$ can be chosen as candidates of proper ARIMA models by applying a iterative procedure based on three stages, just like in section 3.2.

<Table 5> Optimality selection for sales at department stores in terms of exponential smoothing methods

\begin{tabular}{|c|c|c|}
\hline $\begin{array}{c}\text { Model } \\
\text { Goodness-of fit measures }\end{array}$ & $\begin{array}{c}\text { Holt-Winters' } \\
\text { Additive }\end{array}$ & $\begin{array}{c}\text { Holt-Winters' } \\
\text { Multiplicative }\end{array}$ \\
\hline Stationary R-squared & $\mathbf{6 6 8}$ & .586 \\
\hline R-squared & $\mathbf{. 8 9 8}$ & .885 \\
\hline RMSE & $\mathbf{1 0 0 , 8 8 4 . 8 3}$ & $107,297.89$ \\
\hline MAPE & $\mathbf{3 . 3 1}$ & 3.33 \\
\hline MAE & $\mathbf{7 8 , 7 1 6 . 4 6}$ & $79,879.88$ \\
\hline MAXAPE & $\mathbf{1 1 . 0 5}$ & 12.25 \\
\hline MAXAE & $281,694.02$ & $\mathbf{2 6 6 , 4 8 1 . 5 0}$ \\
\hline Normalized BIC & $\mathbf{2 3 . 2 0}$ & 23.32 \\
\hline
\end{tabular}

Based on eight model-fit measures, Holt-Winters' additive seasonality method can be selected as a final and optimal model to forecast the future values of sales at department stores in South Korea as seen from <Table 5> and <Table $6>$.
<Table 6> Optimality selection for sales at department stores in terms of ARIMA models

\begin{tabular}{|c|c|c|}
\hline $\begin{array}{c}\text { Model } \\
\text { Goodness-of fit } \\
\text { measures }\end{array}$ & ARIMA(1,0,0)(1,0,0) $)_{12}$ & ARIMA $(\mathbf{0 , 0 , 3 ) ( 1 , 0 , 0 )})_{12}$ \\
\hline Stationary R-squared & .737 & .739 \\
\hline R-squared & .737 & .739 \\
\hline RMSE & $\mathbf{1 6 2 , 5 1 2 . 8 8}$ & $163,896.74$ \\
\hline MAPE & 5.62 & $\mathbf{5 . 4 1}$ \\
\hline MAE & 128721.85 & $\mathbf{1 2 3 , 8 9 9 . 2 2}$ \\
\hline MAXAPE & $\mathbf{2 1 . 4 5}$ & 23.03 \\
\hline MAXAE & $\mathbf{3 7 2 , 2 0 0 . 3 6}$ & $385,616.36$ \\
\hline Normalized BIC & $\mathbf{2 4 . 1 5}$ & 24.27 \\
\hline $\begin{array}{c}\text { P-value of Box-Ljung } \\
\text { Statistic }\end{array}$ & .102 & .195 \\
\hline
\end{tabular}

<Table 7> Optimal forecasts and two $95 \%$ confidence limits of sales at department stores

\begin{tabular}{|c|c|c|c|}
\hline Time period & Forecasts & $\begin{array}{c}\text { 95\% Lower } \\
\text { Confidence Limit }\end{array}$ & $\begin{array}{c}\text { 95\% Upper } \\
\text { Confidence Limit }\end{array}$ \\
\hline MAR 2017 & $\mathbf{2 , 4 5 5 , 7 3 2}$ & $2,255,076$ & $2,656,388$ \\
\hline April 2017 & $\mathbf{2 , 4 0 7 , 4 9 9}$ & $2,204,712$ & $2,610,286$ \\
\hline May 2017 & $\mathbf{2 , 5 0 9 , 2 6 9}$ & $2,301,766$ & $2,716,772$ \\
\hline June 2017 & $\mathbf{2 , 1 1 6 , 5 2 3}$ & $1,900,891$ & $2,332,154$ \\
\hline July 2017 & $\mathbf{2 , 0 2 9 , 4 9 2}$ & $1,801,740$ & $2,257,244$ \\
\hline August 2017 & $\mathbf{1 , 9 0 1 , 8 6 6}$ & $1,657,716$ & $2,146,017$ \\
\hline Sept 2017 & $\mathbf{2 , 2 6 2 , 2 1 8}$ & $1,997,374$ & $2,527,062$ \\
\hline Oct 2017 & $\mathbf{2 , 5 4 4 , 3 8 6}$ & $2,254,731$ & $2,834,040$ \\
\hline Nov 2017 & $\mathbf{2 , 5 9 1 , 0 4 4}$ & $2,272,750$ & $2,909,338$ \\
\hline Dec 2017 & $\mathbf{2 , 6 8 9 , 9 1 6}$ & $2,339,478$ & $3,040,355$ \\
\hline Jan 2018 & $\mathbf{2 , 2 8 9 , 4 6 1}$ & $1,903,694$ & $2,675,229$ \\
\hline Feb 2018 & $\mathbf{1 , 9 5 6 , 6 6 2}$ & $1,532,668$ & $2,380,655$ \\
\hline
\end{tabular}

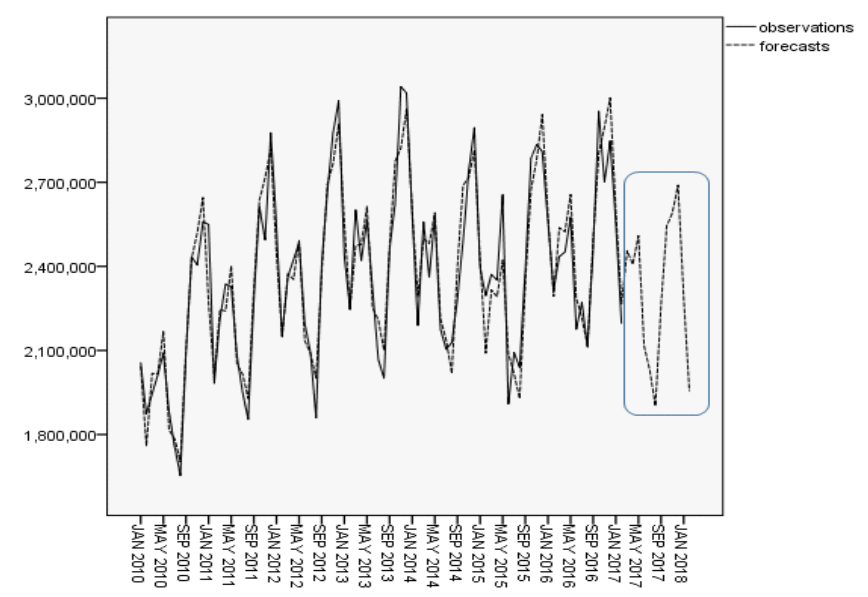

<Figure 4> Optimal forecasts of sales at department stores in South Korea 
By fitting Holt-Winters'additive method to sales of department stores, the predicted values from May in 2017 to February in 2018 appear to fluctuate around the constant level with maintaining the seasonal pattern from <Table 7> and <Figure 4>.

\section{Concluding Remarks and Limitation}

In this research, we forecast both sales at discount store markets and sales at department stores in South Korea by using univariate optimal time series, Holt-Winters' additive seasonality method.

First, optimal forecasts of sales at discount store markets from March in 2017 to February in 2018 in South Korea can be 4451399, 4307456, 4650779, 4338728, 4604838, 4665628, 4984796, 4587536, 4520199, 4785251, 4849130 and 4537496, which are obtained by choosing Holt-Winters' additive seasonality method among several exponential smoothing methods and ARIMA models.

In detail, $\operatorname{ARIMA}(0,1,1)_{12}$ and $\operatorname{ARIMA}(0,0,3)(1,0,0)_{12}$ models are selected by performing optimal procedures of ARIMA model-construction and also three exponential smoothing methods such as Holt's linear, damped linear and Holt-Winters' additive seasonality methods.

Second, optimal forecasts of sales at department stores in South Korea can be 2455732, 2407499, 2509269, 2116523, 2029492, 1901866, 2262218, 2544386, 2591044, 2689916, 2289461 and 1956662, which are, similarly, obtained on Holt-Winters' additive seasonality methods.

Both $\operatorname{ARIMA}(1,0,0)(1,0,0)_{12}$ and $\operatorname{ARIMA}(0,0,3)(1,0,0)_{12}$ models are chosen by carrying out the optimal ARIMA model-construction and also two exponential smoothing

\section{References}

Akaike, H. (1970). Statistical predictor identification. Annals of the Institute of Statistical Mathematics, 22, 203-217.

Anderson, J. R. (1994). Simpler exponentially weighted moving averages with irregular updating periods. Journal of the Operational Research Society, 45, 486.

Anderson, T. W. (1971). The statistical analysis of time series. New York: Wiley.

Andrews, R. L. (1994). Forecasting performance of structural time series models. Journal of Business and Economic Statistics, 12, 129-133.

Archibald, B. C. (1990). Parameter space of the Holt-Winters' model. International Journal of Forecasting. 6, 199-209.

Archibald, B. C., \& Koehler, A. B. (2003). Normalization methods such as and Holt-Winters' additive and Holt-Winters' multiplicative seasonality methods, at the same time.

The shape of the persisting and rather moderate rise of sales at discount stores can be forecasted over the upcoming 12 months, while sales at department stores just keep things tickling over, with both sales maintaining the seasonality pattern.

Empirically calculated estimates of sales at department stores and discount store markets and accurate predicted values of future sales are of much importance for sales planning and policy making. The sensitivity of sales to the transition of its determinants can support policy makers to assess plan B policy options in adjusting future sales at department stores and discount stores or modal shift. Accurate forecasts can provide information on future sales level in the evaluation of sales related projects and sales policies.

Taking into account 2017-2018 forecasts for sales at department stores and at discount store markets, it is of importance to be able to predict future sales magnitude and to produce the useful information for reforming financial conditions and related policies, so that the impacts of any marketing or management scheme can be compared against the do-nothing scenario.

In this paper, we treat two different time series that consist of single realizations recorded sequentially over equally spaced time intervals. Considering indispensable predictor variables and the linear interdependencies among multiple time series, dynamic regression model or vector auto-regression model, as an alternative, can be applied to the underlying time series (Pankratz, 1991; Hatemilton, 2004).

of seasonal factors in Winters' methods. International Journal of Forecasting, 19, 143-148.

Bartolomei, S. M., \& Sweet, A. L. (1989). A note on a comparison of exponential smoothing methods for forecasting seasonal series. International Journal of Forecasting, 5, 111-116.

Bianchi, L., Jarrett, J., \& Hanumara, R. C. (1998). Improving forecasting for telemarketing centers by ARIMA modeling with intervention. International Journal of Forecasting, 14, 497-504.

Bowerman, B. L., O'Connell, R., \& Koehler, A. B. (2005). Forecasting, time series, and regression(4th edition). Pacific Grove, CA: Duxbury Press.

Box, G. E. P., Jenkins, G. M., \& Reinsel, G. C. (1994). Time series analysis: Forecasting and control (3rd ed.). Englewood Cliffs, NJ: Prentice Hall. 
Brown, R. G. (1959). Statistical forecasting for inventory control. New York: McGraw-Hill.

Brown, R. G. (1963). Smoothing, forecasting and prediction of discrete time series. Englewood Cliffs, NJ: Prentice-Hall.

Broze, L., \& Mélard, G. (1990). Exponential smoothing: Estimation by maximum likelihood. Journal of Forecasting, 9, 445-455.

Chatfield, C. (1988). What is the 'best method' of forecasting?. Journal of Applied Statistics, 15, 19-38.

Chatfield, C. (1993). Calculating interval forecasts. Journal of Business and Economic Statistics, 11, 121-135.

Chatfield, C. (1995). Model uncertainty, data mining and statistical inference. Journal of the Royal Statistical Society, Series A, 158, 419-466.

Chatfield, C. (1996). Model uncertainty and forecast accuracy. Journal of Forecasting, 15, 495-508.

Chatfield, C. (1997). Forecasting in the 1990s. Journal of the Royal Statistical Society, Series D, 46, 461-473.

Chatfield, C. (2002). Confessions of a pragmatic statistician. Journal of the Royal Statistical Society, Series $D, 51,1-20$.

Chio, E. Y.(2016). The effects of household debt on household consumption through quantile regression analysis. Journal of Human and Social Science, 17(1), 589-613.

Fuller, W. A. (1976). Introduction to statistical time series. New York: John Wiley \& Sons, Inc.

Gardner, E. S. Jr. (1985). Exponential smoothing: the state of the art. Journal of Forecasting, 4, 1-28.

Gardner, E. S. Jr. (2006). Exponential smoothing: The state of the art Part II. International Journal of Forecasting, 22, 637-677.

Hamilton, J. D. (1994). Time series analysis. Princeton, NJ: Princeton University Press.

Han, S. H., Yang, H. C., \& Kim, J. L.(2015). The impact of service quality on service satisfaction and store loyalty: Service value as a moderator. Journal of Distribution Science, 13(10), 101-108.

Hatemilton, J, A. (2004). Multivariate tests for autocorrelation in the stable and unstable VAR models. Economic Modelling, 21(4), 661-683.

Holt, C. C. (1957). Forecasting seasonality and trends by exponentially weighted moving averages. International Journal of Forecasting, 20(1), 5-10.

Hurvich, C. M., \& Tsai, C. L. (1990). The impact of model selection on inference in linear regression. American Statistician, 44, 214-217.
Hwang, J. Y., \& Lee, S. H. (2015). Household debt and its impacts on consumption and income in Korea. Financial Policy Reviews, 17(2), 127-153.

Jeong, D. B. (2009). Demanding forecasting of time series I. Seoul, Korea: Hannarae Academy.

Jeong, D. B. (2010). Demanding forecasting of time series I. Seoul, Korea: Hannarae Academy.

Jeong, D. B. (2016). The degree of association between traditional markets and related major factors in Korea. Journal of Distribution Science, 14(7), 5-14.

Jeong, D. B. (2016). Optimal forecasting for sales at convenience stores in Korea using seasonal ARIMA-Intervention model. Journal of Distribution Science, 14(11), 83-90.

Kim, S. M., Ahn, J. S., \& Shim, G. E.(2014). Critical factors for sales of department stores - focused on comparison of influence on sales between location and non-location factors. Journal of Urban Design Institute of Korea, 15(1), 51-66.

Lee, S. N. (2016). An empirical study on affecting factors of household debts. Journal of Digital Convergence, 14(5), 177-183.

Ljung, G. M., \& Box, G. E. P. (1978). On a measure of lack of fit in time series models. Biometrika, 65, 297-303.

Pankratz, A. (1983). Forecasting with univariate Box-Jenkins models: Concepts and cases. New York: John Wiley \& Sons, Inc.

Pankratz, A. (1991). Forecasting with dynamic regression models. New York: John Wiley \& Sons, Inc.

Roberts, S. A. (1982). A general class of Holt-Winters type forecasting models. Management Science, 28, 808-820.

Rosanna, R. J., \& Seater, J. J. (1995). Temporal aggregation and economic time series. Journal of Business and Economic Statistics, 13, 441-451.

Rosas, A. L., \& Guerrero, V. M. (1994). Restricted forecasts using exponential smoothing techniques. International Journal of Forecasting, 10, 515-527.

Tsay, R. S., \& Tiao, G. C. (1984). Consistent estimates of autoregressive parameters and extended sample autocorrelation function for stationary and nonstationary ARMA Models. Journal of the American Statistical Association, 79, 84-96.

Trigg, D. W., \& Leach, D. H. (1967). Exponential smoothing with an adaptive response rate. Operational Research Quarterly, 18, 53-59.

Winters, P. R. (1960). Forecasting Sales by Exponentially Weighted Moving Averages. Management Science, 6(3), 324-342. 